University of Nebraska - Lincoln

DigitalCommons@University of Nebraska - Lincoln

Biochemistry -- Faculty Publications

Biochemistry, Department of

2001

\title{
The WASp-like protein Scar regulates macropinocytosis, phagocytosis and endosomal membrane flow in Dictyostelium
}

\author{
David J. Seastone \\ Pikeville College School of Osteopathic Medicine, Pikeville, KY \\ Ed Harris \\ University of Nebraska - Lincoln, eharris5@unl.edu \\ Lesly A. Temesvari \\ LSU Health Sciences Center, Shreveport, LA \\ James E. Bear \\ Emory University School of Medicine, Atlanta, GA \\ Charles L. Saxe \\ Emory University School of Medicine, Atlanta, GA
}

See next page for additional authors

Follow this and additional works at: https://digitalcommons.unl.edu/biochemfacpub

Part of the Biochemistry, Biophysics, and Structural Biology Commons

Seastone, David J.; Harris, Ed; Temesvari, Lesly A.; Bear, James E.; Saxe, Charles L.; and Cardelli, James, "The WASp-like protein Scar regulates macropinocytosis, phagocytosis and endosomal membrane flow in Dictyostelium" (2001). Biochemistry -- Faculty Publications. 43.

https://digitalcommons.unl.edu/biochemfacpub/43

This Article is brought to you for free and open access by the Biochemistry, Department of at DigitalCommons@University of Nebraska - Lincoln. It has been accepted for inclusion in Biochemistry -- Faculty Publications by an authorized administrator of DigitalCommons@University of Nebraska - Lincoln. 


\section{Authors}

David J. Seastone, Ed Harris, Lesly A. Temesvari, James E. Bear, Charles L. Saxe, and James Cardelli 


\title{
The WASp-like protein Scar regulates macropinocytosis, phagocytosis and endosomal membrane flow in Dictyostelium
}

\author{
David J. Seastone ${ }^{1, \ddagger}$, Ed Harris ${ }^{1}$, Lesly A. Temesvari², James E. Bear ${ }^{3, *}$, Charles L. Saxe ${ }^{3}$ \\ and James Cardelli $1,2, \pi$ \\ 1Department of Microbiology and Immunology, Louisiana State University Health Sciences Center Shreveport, LA 71130, USA \\ 2The Feist-Weiller Cancer Center, Louisiana State University Health Sciences Center Shreveport, LA 71130, USA \\ 3Department of Cell Biology, Emory University School of Medicine, Atlanta, GA 30322-3030, USA \\ *Present address: Department of Biology, Massachusetts Institute of Technology, Cambridge, MA, USA \\ łPresent address: Department of Biochemistry, Pikeville College School of Osteopathic Medicine, Pikeville, KY 41501, USA \\ १Author for correspondence (e-mail: jcarde@ Isumc.edu) \\ Accepted 24 April 2001 \\ Journal of Cell Science 114, 2673-2683 @ The Company of Biologists Ltd
}

\section{SUMMARY}

Scar, a member of the WASp protein family, was discovered in Dictyostelium discoideum during a genetic screen for second-site mutations that suppressed a developmental defect. Disruption of the scar gene reduced the levels of cellular F-actin by $\mathbf{5 0 \%}$. To investigate the role of Scar in endocytosis, phagocytosis and endocytic membrane trafficking, processes that depend on actin polymerization, we have analyzed a Dictyostelium cell line that is genetically null for Scar. Rates of fluid phase macropinocytosis and phagocytosis are significantly reduced in the scar $^{-}$cell-line. In addition, exocytosis of fluid phase is delayed in these cells and movement of fluid phase from lysosomes to post-lysosomes is also delayed. Inhibition of actin polymerization with cytochalasin A resulted in similar phenotypes, suggesting that Scar-mediated polymerization of the actin cytoskeleton was important in the regulation of these processes. Supporting this conclusion, fluorescence microscopy revealed that some endo-lysosomes were ringed

\section{INTRODUCTION}

Wiskott-Aldrich syndrome is an X-linked immunodeficiency disease that results from the failure of both $\mathrm{T}$ and $\mathrm{B}$ cell function and additional defects in monocyte chemotaxis (Ochs et al., 1980). As a result, patients with this disease not only have compromised immune function, but also have increased incidence of thrombocytopenia and are more susceptible to lymphomas and leukemias (Kirchhausen and Rosen, 1996). Recently, the gene responsible for this disease was identified (Derry et al., 1994) and found to encode a $54 \mathrm{kDa}$ protein. The WASp protein can associate with filamentous (F)-actin and is hypothesized to participate in $\mathrm{Cdc} 42$ mediated signal transduction pathways that regulate the polymerization of $\mathrm{F}$ actin (Aspenstrom et al., 1996; Kolluri et al., 1996; Symons et al., 1996). Although the originally identified WASp protein was shown to be expressed only in cells of hematopoietic origin (Derry et al., 1994), another closely related protein, $\mathrm{N}$ WASP, was later found to be ubiquitously expressed but enriched in neural tissue (Miki et al., 1996). with $\mathrm{F}$-actin in control cells but no $\mathrm{F}$-actin was detected associated with endo-lysosomes in Scar null cells. Disruption of the two genes encoding the actin monomer sequestering protein profilin in wild-type cells causes defects in the rate of pinocytosis and fluid phase efflux. Consistent with a predicted physical interaction between Scar and profilin, disrupting the scar gene in the profilin null background results in greater decreases in the rate of fluid phase internalization and fluid phase release compared to either mutant alone. Taken together, these data support a model in which Scar and profilin functionally interact to regulate internalization of fluid and particles and later steps in the endosomal pathway, probably through regulation of actin cytoskeleton polymerization.

Key words: Scar, Macropinocytosis, Phagocytosis, Actin
It has been proposed that the various forms of WASp interact with several other proteins in order to induce the polymerization of F-actin. For instance, it was shown that, through its proline-rich domains, WASp can bind to the adaptor proteins Nck and Grb2 (Rivero-Leczano et al., 1995; She et al., 1997). In addition, WASp can bind a novel protein termed WIP (Wiskott-Aldrich syndrome protein-interacting protein) (Ramesh et al., 1997). Verprolin, a WIP ortholog, in turn, was demonstrated to control cell polarity in yeast (Vaduva et al., 1999). WIP also binds to the adaptor protein Nck, suggesting that Nck, WASp and Wip might form complexes that regulate the actin polymerization machinery (Anton et al., 1998). Further evidence for the involvement of Wip/WASp in actin polymerization has come from experiments showing that sitedirected mutations in WASp impair its interaction with Wip and might lead to Wiskott-Aldrich syndrome (Stewart et al., 1999). Finally, it has also been established that N-WASp can bind actin monomers and sequester the profilin through its polyproline domain, and that this association leads to plasma membrane alterations (Suetsugu et al., 1998). 
In a genetic screen for second-site suppressors of a mutation in one of the cAMP receptors, another protein that has significant homology to WASp, Scar, was identified in $D$. discoideum (Bear et al., 1998). Subsequently, a Scar homolog, termed h-Scarl or Wave, was identified in humans and other vertebrates (Bear et al., 1998; Miki et al., 1998). When scar was disrupted in Dictyostelium, it was able to restore the normal development to cells that were null for the cAMP receptor cAR2 (Saxe et al., 1993). When scar was disrupted in a wild-type background, both morphogenetic and actin cytoskeletal defects were seen in Dictyostelium (Bear et al., 1998; C.L.S. et al., unpublished), indicating that Scar might behave in a similar manner to the closely related protein WASp. Interestingly, alignment of the two proteins showed that Scar shares many of the same domains as WASp, including a Cterminal acidic domain, a short WASp-homology domain (shown to interact with actin) and a polyproline rich domain (shown to interact with profilin). However, unlike WASp, Scar family members do not contain a Cdc42/Rac1 interactive binding (CRIB) domain and, instead have a novel protein region, termed a Scar homology domain (SHD). Finally, whereas WASp contains an N-terminal domain related to pleckstrin homology domains, Scar does not. This evidence suggests that WASp and Scar have both overlapping and distinct functions (reviewed in Mullins, 2000).

Recent data (Machesky et al., 1999; Rohatgi et al., 1999) have provided perhaps the most compelling evidence for a role for Scar/WASp in regulating actin cytoskeleton organization. These studies confirmed that Scar/WASp bound to and stimulated the activity of the Arp $2 / 3$ complex, a seven protein complex that was previously shown to be important in the dendritic nucleation involved in forming branching F-actin (Mullins et al., 1997; Mullins et al., 1998; Welch et al., 1997). The proposed dendritic nucleation model suggests that Arp2/3 associates with actin on the side of existing filaments and acts as a cap for the pointed end of a newly formed actin filament. Scar is believed to bind to the complex and activate the nucleation activity of Arp $2 / 3$, causing the nascent filament to grow in the barbed-end direction. Thus, cells can control the localized polymerization of actin to form lamellipodia by adding on to already-existing filaments (Weiner et al., 1999; Svitkina and Borisy, 1999).

The Arp2/3 complex was originally discovered by searching for binding partners for the actin binding protein profilin in Acanthamoeba (Machesky et al., 1994). It was subsequently found that one of the subunits of the Arp2/3 complex could bind to actin (Mullins et al., 1997). Around the same time, it was found (Suetsugu et al., 1998) that N-WASp could also bind profilin at its polyproline stretch of amino acids, suggesting the possibility that Scar or WASp binds to profilin-actin to recruit it to the Arp2/3 complex. This model is probably an oversimplification, as profilin inhibits the polymerization of $\mathrm{F}$ actin in vitro in the presence of Arp2/3 and Scar (Machesky et al., 1999).

The exact function of profilin remains unknown, as seemingly conflicting experimental results have been published. It is now hypothesized that at low concentrations profilin stimulates actin assembly (Vinson et al., 1998), while at high concentrations it behaves as an actin monomer sequestering protein and prevents F-actin assembly (Carlsson et al., 1977). Deletion of the two genes encoding profilin in
Dictyostelium results in a number of phenotypic changes (Haugwitz et al., 1994). Motility is reduced and mutant cells are large and contain a broad rim of cortical actin, suggesting that profilin acts primarily to sequester monomeric actin in Dictyostelium. In addition, the profilin null mutants show defects in endosomal trafficking and internalization (Temesvari et al., 2000).

Two recent papers demonstrate that WASp also plays a role in the regulation of phagocytosis (May et al., 2000; Lorenzi et al., 2000). In order to gain more insight into how WASp-like proteins might function in the regulation of endocytosis and endo-lysosomal membrane trafficking, processes dependent on actin regulation, we have analyzed a $D$. discoideum cell line in which the gene encoding Scar has been disrupted (Bear et al., 1998). Previous studies of Dictyostelium have demonstrated the importance of the actin cytoskeleton in the regulation of vesicle trafficking and endocytic pathways (Buczynski et al., 1997; Seastone et al., 1998; Maniak et al., 1995; Hacker et al., 1997; Temesvari et al., 2000). The current studies demonstrate that a knockout of the gene encoding Scar results in defects in macropinocytosis and phagocytosis. In addition, the scar disruption causes a block in the trafficking and release of fluid phase from cells. Finally, disrupting the scar gene in a Dictyostelium mutant null for both profilin proteins further reduced the levels of fluid phase pinocytosis and exocytosis observed in the profilin mutant. Taken together, these results suggest a model in which profilin and Scar act in parallel and/or in concert to regulate the polymerization of F-actin that is critical for multiple endocytic processes.

\section{MATERIALS AND METHODS}

\section{Organism}

Dictyostelium strains were grown axenically in HL5 medium (1\% Oxoid proteose peptone, $1 \%$ glucose, $0.5 \%$ yeast extract (Difco), 2.4 $\mathrm{mM} \mathrm{Na} 2 \mathrm{HPO}_{4} ; \mathrm{pH} 6.5$ ) in $175 \mathrm{~cm}^{2}$ tissue culture flasks (Sarstedt) at $19^{\circ} \mathrm{C}$. Generation of the $s c a r^{-}$cells $\left(s c r \mathrm{~A}^{-}\right)$from a Ax3 derived strain is described elsewhere (Bear et al., 1998). Mutant cells were cultured in HL5 medium supplemented with $10 \mu \mathrm{g} \mathrm{ml}{ }^{-1}$ blasticidin (Calbiochem).

Profilin/Scar triple null cells $\left(\mathrm{pI}^{-} / \mathrm{II}^{-} / \mathrm{scar}^{-}\right)$were constructed by introducing the 9A/O7 plasmid (Bear et al., 1998) into the profilin double null mutant (provided by M. Schleicher) and selecting for blasticidin-resistant transformants. The genotype was confirmed by PCR-based detection of the Scar-blastocidin cassette as previously described (Bear et al., 1998). These cells were maintained on HL5 medium in tissue culture dishes or on lawns of Klebsiella aerogenes.

\section{Phagocytosis, fluid phase pinocytosis and exocytosis assays}

For phagocytosis, fluid phase pinocytosis and exocytosis assays, exponentially growing cells were harvested from T-175 tissue culture flasks (Sarstedt) and resuspended in growth medium at a titer of $3 \times 10^{6}$ cells $\mathrm{ml}^{-1}$. For phagocytosis assays, cells were exposed to $1 \mu \mathrm{m}$ fluorescent crimson latex beads (Molecular Probes) in HL5 medium at a concentration of 50 beads per cell. Cells and beads were shaken at $150 \mathrm{rpm}$ in $25 \mathrm{ml}$ Erlenmeyer flasks for 90 minutes. At various times, $1 \mathrm{ml}$ aliquots of cells were harvested by centrifugation $(1000$ $\boldsymbol{g}$ for 5 minutes), washed twice with cold HL5 growth medium, and once with sucrose buffer ( $5 \mathrm{mM}$ glycine, $100 \mathrm{mM}$ sucrose, $\mathrm{pH}$ 8.5). Cells were lysed with $0.5 \%$ Triton $\mathrm{X}-100$ and the intracellular fluorescence was measured by spectrofluorimetry using $625 \mathrm{~nm}$ wavelength for excitation and $645 \mathrm{~nm}$ for emission. The fluorescence 
of each of the samples was normalized to total cell protein to account for any differences in cell sizes between the strains. For fluid phase pinocytosis assays, FITC-dextran (relative molecular mass $\left(M_{\mathrm{r}}\right)$ 70,000 , Sigma) was incubated with shaking cultures of cells in growth medium to a final concentration of $2 \mathrm{mg} \mathrm{ml}^{-1}$ for 2 hours. At various times, cells were harvested and lysed with $0.5 \%$ Triton X-100, and the intracellular fluorescence was calculated with a spectrofluorimeter using $492 \mathrm{~nm}$ for excitation and $525 \mathrm{~nm}$ for emission. For exocytosis assays, cells were loaded for 3 hours with 70,000 $M_{\mathrm{r}}$ FITC-dextran. The cells were washed twice with cold HL5 medium and resuspended in growth medium. At various times, the cells were harvested, lysed with $0.5 \%$ Triton $\mathrm{X}-100$, and the intracellular fluorescence was determined as described above. To determine the percent of fluorescence remaining in the cells, the fluorescence value at each time point was compared with the fluorescence at time $T=0$, which was given a value of $100 \%$.

\section{pH flux assays}

For $\mathrm{pH}$ flux assays, cells were harvested from T-175 flasks and resuspended in HL5 growth medium containing FITC-dextran $(5 \mathrm{mg}$ $\mathrm{ml}^{-1}$ ) at a titer of $3 \times 10^{6}$ cells $\mathrm{ml}^{-1}$. After a 10 minute pulse with the FITC-dextran, cells were harvested by centrifugation (1000 $g$ for 5 minutes) and resuspended in growth medium without FITC-dextran. At various times during the chase period, $1 \mathrm{ml}$ aliquots of cells were harvested, washed twice with HL5 medium, once with MES buffer $(50 \mathrm{mM})$, and then resuspended in $1 \mathrm{ml}$ MES. The ratio of the emission value at $525 \mathrm{~nm}$ (after excitation at $450 \mathrm{~nm}$ ) to that after excitation at $495 \mathrm{~nm}$ was calculated and compared to a FITC fluorescence/pH standard curve to obtain the vesicular $\mathrm{pH}$.

\section{Fluorescence microscopy}

Cells were harvested from T-25 tissue culture flasks and incubated in HL5 medium with the fluid phase markers RITC-dextran $\left(2 \mathrm{mg} \mathrm{ml}^{-1}\right)$ or FITC-dextran $\left(2 \mathrm{mg} \mathrm{ml}^{-1}\right)$. For macropinocytosis measurements, cells were pulsed for 5 minutes while attached to coverslips. For experiments designed to examine the steady state appearance of endolysosomal vesicles, cells shaking in suspension were pulsed for 1 hour with FITC-dextran $\left(2 \mathrm{mg} \mathrm{ml}^{-1}\right)$ or RITC-dextran $\left(2 \mathrm{mg} \mathrm{ml}^{-1}\right)$ and washed with HL5 growth medium. The cells were resuspended in fresh growth medium and Lysosensor Green (Molecular Probes, Eugene, OR) was added at a dilution of 1:1000. Cells were immediately spotted onto plastic coverslips and, after 10 minutes, they were gently rinsed with HL5 medium and examined using fluorescence microscopy.

F-actin staining of wild-type, profilin and profilin/Scar null mutants was performed as described (Bear et al., 1998). Briefly, growing cells were collected, allowed to adhere to glass coverslips, washed with PBS and stained with PBS containing $400 \mathrm{nM}$ TRITC-phalloidin (Sigma). Cells were viewed on a Model 510 confocal microscope (Carl Zeiss) or an Olympus Ax70 epifluorescence microscope. F-actin was visualized in vivo using cell lines expressing GFP-ABD, a fusion protein previously shown to bind intracellular F-actin with high specificity.

\section{Lysosomal hydrolase secretion assay}

Cells were cultured in HL5 growth medium and were harvested from T-175 flasks, washed and the steady state intracellular and extracellular levels of $\alpha$-mannosidase activity were assayed as described (Seastone et al., 1998).
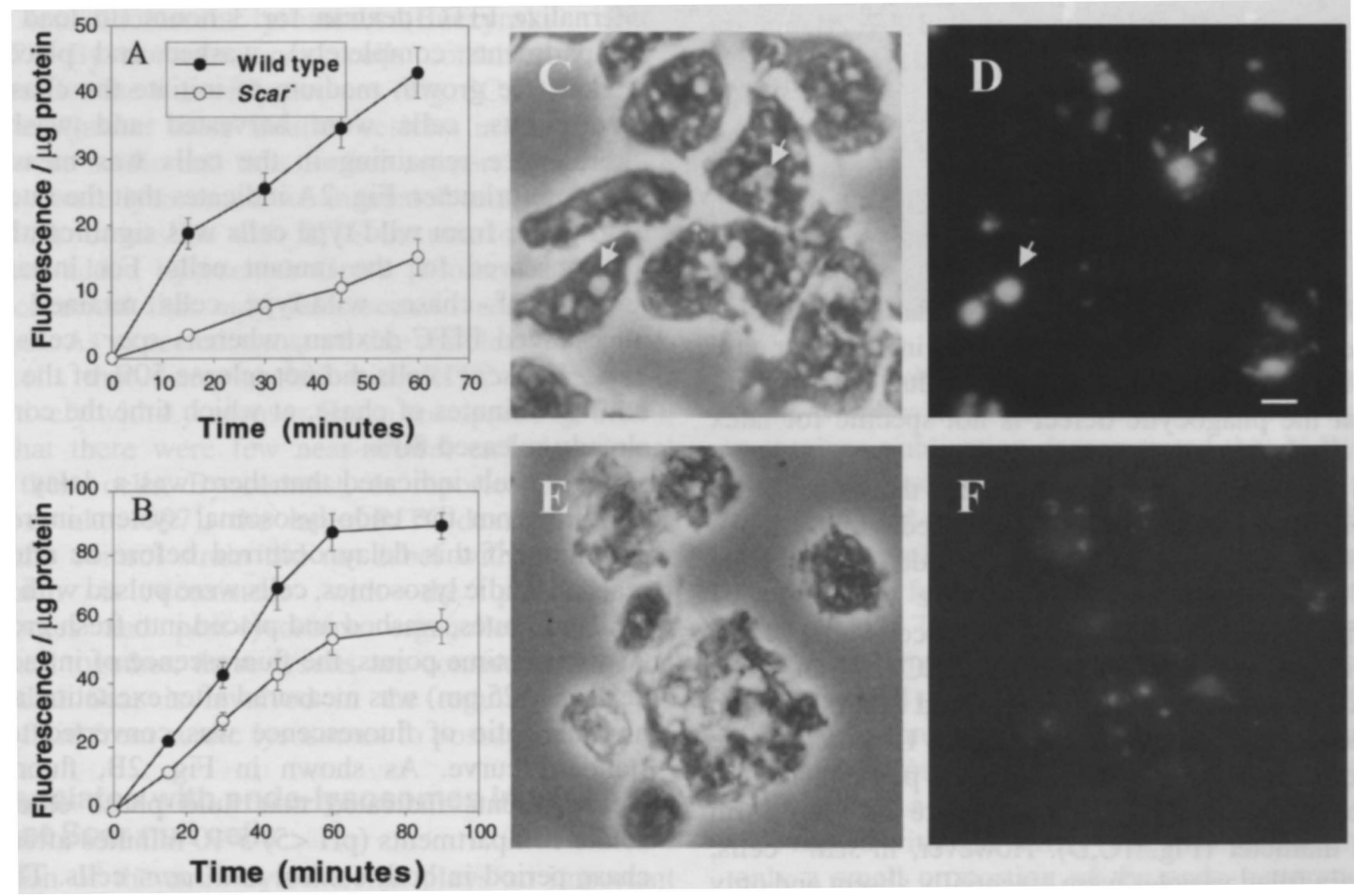

Fig. 1. scar ${ }^{-}$cells are defective in phagocytosis, fluid phase pinocytosis and macropinocytosis. To determine the rates of phagocytosis, cells were incubated with $1 \mu \mathrm{m}$ fluorescent latex beads or FITC-dextran for the indicated times and the intracellular fluorescence was calculated using a spectrofluorimeter. The fluorescence value at each time point was normalized to protein load to account for any difference in cell size among the strains. (A) scar ${ }^{-}$cells internalized beads at a rate two to three times less than that of control cells, indicating that the mutant was defective in phagocytosis $(n=6)$. (B) scar ${ }^{-}$cells internalized FITC-dextran at half the rate of control cells, indicating that the mutant also defective in fluid phase pinocytosis $(n=5)$. (C-F) Cells were incubated with $2 \mathrm{mg} \mathrm{ml}^{-1}$ FITC-dextran for 10 minutes, washed twice in fresh HL5 growth medium, spotted onto plastic coverslips and examined using phase contrast $(\mathrm{C}, \mathrm{E})$ or fluorescence $(\mathrm{D}, \mathrm{F})$ microscopy. Control cells (C,D) contained many large macropinosomal vesicles (arrows), whereas the $s c a r^{-}$cells (E,F) contained no large macropinosomes. Bar, $2.5 \mu \mathrm{m}$. 
Fig. 2. scar $^{-}$cells are defective in fluid phase exocytosis. To examine exocytosis, wild-type and scar ${ }^{-}$cells were loaded with FITC-dextran for 3 hours, washed and allowed to efflux FITC-dextran for the indicated times prior to harvesting and fluorescence measurement. The percentage FITCdextran remaining inside the cell was calculating by comparing the fluorescence values at each of the time points to the value at time $T=0$.

(A) The average of four independent experiments, showing that $s c a r^{-}$cells are defective in exocytosis. Whereas wild-type cells have released $50 \%$ of the FITC-dextran from the cell by 50
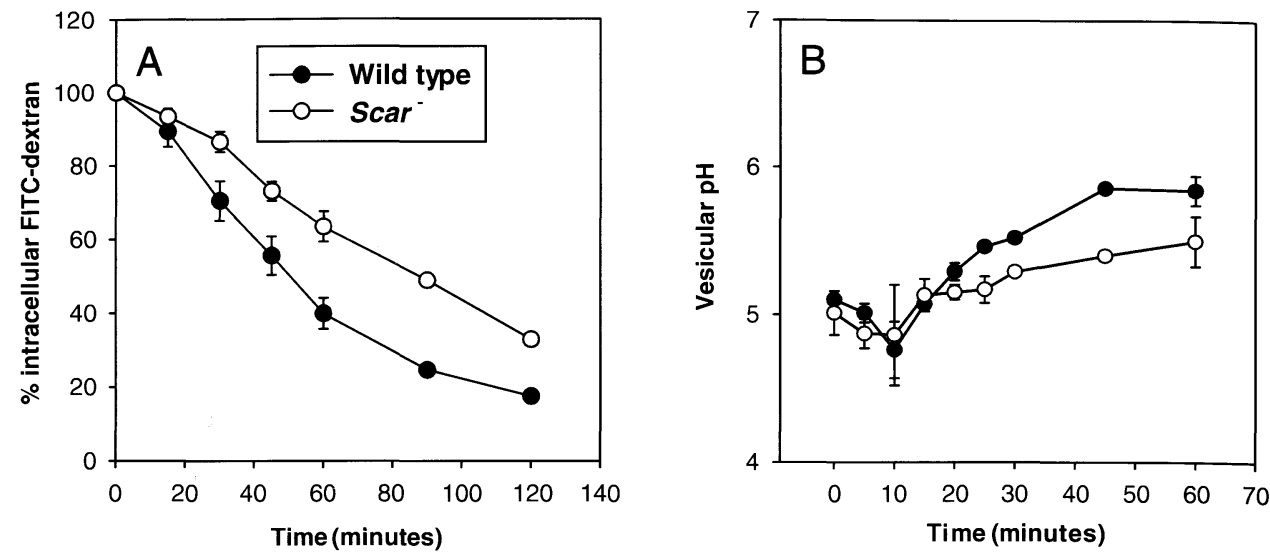

minutes, scar $^{-}$cells required nearly twice as long (90 minutes) to exocytose $50 \%$ of the FITC-dextran. (B) The vesicular pH was calculated over time as described in Materials and Methods. Fluid phase entered acidic vesicles rapidly (within 10 minutes into the chase period in both control Ax3 and $s c a r^{-}$cells). However, the fluid phase only slowly left lysosomes in scar ${ }^{-}$cells and did not reach more neutral pH postlysosomes until after 60 minutes into the chase period, whereas, in wild-type cells, the fluid phase entered the post-lysosomes within 45 minutes.

\section{RESULTS}

\section{Disruption of scar reduces the rates of phagocytosis and fluid phase endocytosis}

To determine the role of Scar in regulating phagocytosis and fluid phase endocytosis, processes previously demonstrated to require actin polymerization (Lamaze et al, 1997; Maniak et al., 1995; Hacker et al., 1997), wild-type and Scar null cells were incubated with $1 \mu \mathrm{m}$ fluorescent latex beads or FITCdextran. At various times, cells were washed and intracellular fluorescence was measured. As shown in Fig. 1A, the rate of phagocytosis of the latex particles was decreased by $80 \%$ in scar ${ }^{-}$cells compared to control Ax 3 cells and the rate of uptake of the fluid phase marker FITC-dextran was decreased by $40 \%$ (Fig. 1B). The rate of uptake of fluorescently labeled Escherichia coli was also reduced by $80 \%$ in the Scar null strain as compared to control cells (results not shown), indicating that the phagocytic defect is not specific for latex particles.

Much of the uptake of fluid phase that occurs in Dictyostelium is through the actin-based process of macropinocytosis (Hacker et al., 1997). In order to determine whether the decrease in fluid phase uptake was due to a decrease in macropinocytosis, we incubated cells attached to coverslips with the fluid phase marker FITC-dextran for 5 minutes, fixed cells with $1 \%$ formaldehyde and examined them by fluorescence microscopy. As shown in Fig. 1, in most of the control Ax3 cells after a 5 minute pulse, fluid phase resided in one or two macropinosomes that range in size between $2 \mu \mathrm{m}$ and $3 \mu \mathrm{m}$ in diameter (Fig. 1C,D). However, in scar cells, large fluid phase filled vesicles were essentially absent and only a few, much smaller, vesicles were observed (Fig. 1E,F). Therefore, it appeared that the scar cells were defective in macropinocytosis as well as in phagocytosis.

\section{Scar null cells are defective in late endo-lysosomal trafficking events}

Within minutes of internalization, fluid is transported to acidic lysosomes (Aubry et al., 1993), followed by transported from lysosomes to neutral $\mathrm{pH}$ post-lysosomes (Padh et al., 1993), from where it is released into the extracellular milieu beginning approximately 45 minutes after internalization. To determine whether Scar played a role in regulating the release of fluid phase material from the endo-lysosomal system of Dictyostelium, wild-type and mutant cells were allowed to internalize FITC dextran for 3 hours (to load all endocytic compartments completely), washed and placed back into marker-free growth medium to initiate the chase. At various time points, cells were harvested and washed, and the fluorescence remaining in the cells was measured using a spectrofluorimeter. Fig. $2 \mathrm{~A}$ indicates that the rate of release of fluid phase from wild-type cells was significantly higher than that observed for the mutant cells. For instance, after 50 minutes of chase, wild-type cells retained $50 \%$ of the internalized FITC-dextran, whereas scar ${ }^{-}$cells still retained $75 \%$. The scar cells did not release $50 \%$ of the FITC-dextran until 90 minutes of chase, at which time the control cells had already released $80 \%$.

This result indicated that there was a delay in the release of fluid from the endo-lysosomal system in scar cells. To determine if this delay occurred before or after fluid phase reached acidic lysosomes, cells were pulsed with FITC-dextran for 10 minutes, washed and placed into fresh growth medium. At various time points, the fluorescence of intracellular FITCdextran $(525 \mathrm{~nm})$ was measured after excitation at 450 and 495 $\mathrm{nm}$; the ratio of fluorescence was converted to $\mathrm{pH}$ using a standard curve. As shown in Fig. 2B, fluorescence ratio measurements indicated that fluid phase entered the most acidic compartments $(\mathrm{pH}<5)$ 5-10 minutes after initiating the chase period in both control and scar cells. This result is in accordance with previously published studies showing that fluid phase normally enters acidic lysosomes within minutes after internalization (Padh et al., 1993). However, in control cells, the fluid phase marker rapidly entered more neutral $\mathrm{pH}$ compartments $(\mathrm{pH}>5.5)$, whereas, in $s c a r^{-}$cells, this process was delayed, suggesting that fluid phase was retained in acidic compartments (Fig. 2B).

As an alternative approach to determine whether fluid phase 
Fig. 3. scar $^{-}$cells contain mostly small acidic vesicles. Phase contrast $(A, C)$ and fluorescent $(B, D)$ microscopic images of control (A,B) and scar ${ }^{-}$cells (C,D). (A-D) Cells were incubated with FITC-dextran for 1 hour, washed and spotted onto coverslips prior to examination. In control cells $(A, B)$, vesicles of many different sizes were present, including large post-lysosomal and macropinosomal vesicles (arrows). By contrast, scar- cells contained primarily smaller vesicles. (E,F) scar- cells were incubated with RITC-dextran for 1 hour, washed and further incubated with Lysosensor Green for 10 minutes. After spotting cells on coverslips, they were examined using the red channel (E) or the green channel $(F)$ of the fluorescence microscope. Most of the RITC-dextranpositive vesicles (E) also stained with Lysosensor Green (F), indicating that most of the vesicles in the scar $^{-}$cells were acidic. Bar, $5 \mu \mathrm{m}$.

accumulated in acidic lysosomes in the mutant cells, we incubated scar ${ }^{-}$and wild-type cells with FITCdextran for 1 hour and then allowed cells to attach to coverslips. Subsequent examination by fluorescence microscopy revealed that control cells (Fig. 3A,B) contained fluorescent vesicles of many different sizes including large post-lysosomes and macropinosomes (vesicles $>0.5 \mu \mathrm{m}$ marked with arrows) and smaller lysosomes $(<0.5 \mu \mathrm{m}$, marked with an arrow head). We have previously demonstrated that these large, more fluorescent vesicles are much less acidic than the smaller less fluorescent lysosomes (Buczynski et al., 1997). By contrast, scar ${ }^{-}$cells contained primarily vesicles the size of lysosomes (Fig. 3C,D). To determine whether these smaller vesicles in the scar ${ }^{-}$cells were acidic and thus further support the idea that they were lysosomes, we incubated mutant cells attached to coverslips with RITC-dextran for 1 hour and then added Lysosensor Green (Molecular Probes), a chemical that only fluoresces in acidic compartments. As expected, most of the vesicles in the scar cells that were labeled with RITC-dextran also labeled positively with Lysosensor Green (compare Fig. 3E,F), indicating that there were few near-neutral endo-lysosomal vesicles in these cells. By contrast, as reported previously (Buczynski et al., 1997), the large RITC-dextran positive vesicles in the control strain did not label with Lysosensor Green, which is consistent with the presence of macropinosomes and post-lysosome organelles (data not shown). Taken together, these results are consistent with the hypothesis that Scar is involved in the regulation of the transport of fluid from acidic lysosomes to post-lysosomes.

\section{F-actin associates with endo-lysosomes in wild-type cells but not Scar null cells}

Polymerization of the actin cytoskeleton plays an important role in the regulation of the endo-lysosomal system of several different cell types including mammalian cells, yeast and Dictyostelium (Lamaze et al., 1997; Kubler and Riezman, 1993; Jenne et al., 1998; Maniak et al., 1995; Hacker et al., 1997; Seastone et al., 1998; Seastone et al., 1999). Scar might act to regulate the endo-lysosomal system by controlling the polymerization of actin through recruitment and/or activation of the Arp2/3 complex (Machesky et al., 1999). Scar could
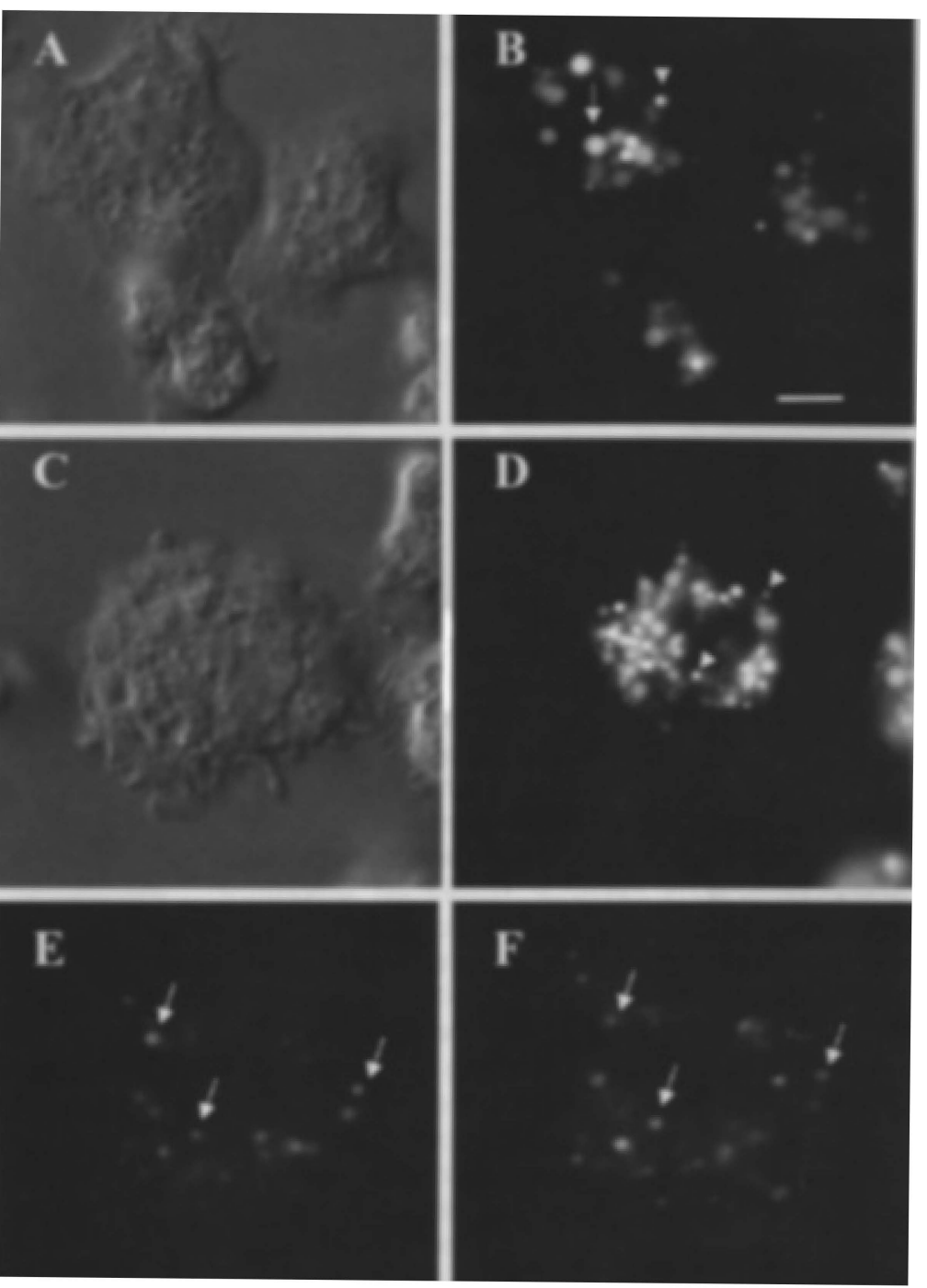

bind to endo-lysosomes and initiate the polymerization of Factin, which is necessary for endosomal fluid transport. In fact, a previous publication demonstrated that N-WASp associated with endo-lysosomes and stimulated F-actin polymerization that propelled lysosomes (Taunton et al., 2000). A prediction of this hypothesis is that Scar null cells should contain significantly fewer endo-lysosomes ringed with F-actin than control cells. To test this hypothesis, we first analyzed control cells expressing GFP-ABD protein, which has previously been demonstrated to bind to F-actin (Pang et al., 1998). Cells were allowed to internalize Texas Red (TR)-dextran for 1 hour to load the endosomal compartment. Fig. 4 shows that control cells contain a few TR-dextran-positive endo-lysosomes (Fig. 4B) ringed with GFP-ABD (Fig. 4A). Although, in most cells, only a small proportion of the endo-lysosomes were ringed with GFP-ABD, all of the GFP-ABD-positive vesicles contained TR-dextran, supporting the concept that GFP-ABD positive vesicles were endo-lysosomal.

Next, control and Scar null cells were fixed and stained with TR-phalloidin to visualize F-actin. Fluorescent dextran was not included in this experiment because the fixation conditions necessary to visualize F-actin preclude retention of fluid in vesicles. Control cells contained on average between one and 
Fig. 4. F-Actin rings endo-lysosomes in control but not in scar ${ }^{-}$cells. Cells expressing GFP-ABD (A) were incubated with RITC-dextran in growth medium for 1 hour (B), recovered by centrifugation and fixed with formaldehyde prior to visualization using a fluorescence microscope. These two panels show that all the vesicles ringed with Factin were endo-lysosomal in nature. (C-F) Control cells (C,D) and scar ${ }^{-}$cells (E,F) were fixed and decorated with fluorescent phalloidin to visualize F-actin.

(C,E) Fluorescent images; (D,F) Differential interference contrast (DIC) images. Bar, $5 \mu \mathrm{m}$.

three F-actin-positive vesicular structures (Fig. 4C,D), demonstrated above to be endosomes. By contrast, no F-actin ringed structures were observed in $>100$ Scar null cells (Fig. 4E,F), suggesting that Scar is necessary for the recruitment or polymerization of F-actin to endo-lysosomes.

Three approaches were used to determine whether Scar associated with endo-lysosomes. In the first approach, cells expressing GFP-Scar were loaded with TR-dextran and viewed using a fluorescence microscope. The GFP-Scar distribution appeared cytosolic, comparable to GFP expressed alone (results not shown). This distribution is not surprising because $>90 \%$ of Scar is cytosolic (based on subcellular fractionation). No TR-dextran-positive vesicles were ringed with GFP-Scar, although the low level of expression of GFP-Scar might have prevented detection. Unfortunately, higher levels of expression of GFP-Scar proved toxic to cells. In the second approach, immunofluorescence microscopic approaches were used define the location of Scar in cells and, as observed for GFP-Scar, the fluorescence appeared diffuse and cytosolic in nature. In the third approach, cells loaded with iron-dextran were fractionated on a magnetic column using a published technique (Temesvari et al., 1994) that has been demonstrated to yield highly pure endosomes and lysosomes. As demonstrated by western blot analysis, Scar was found to associate with endo-lysosomes but the level of association was not much greater than that observed for other cytosolic markers (results not
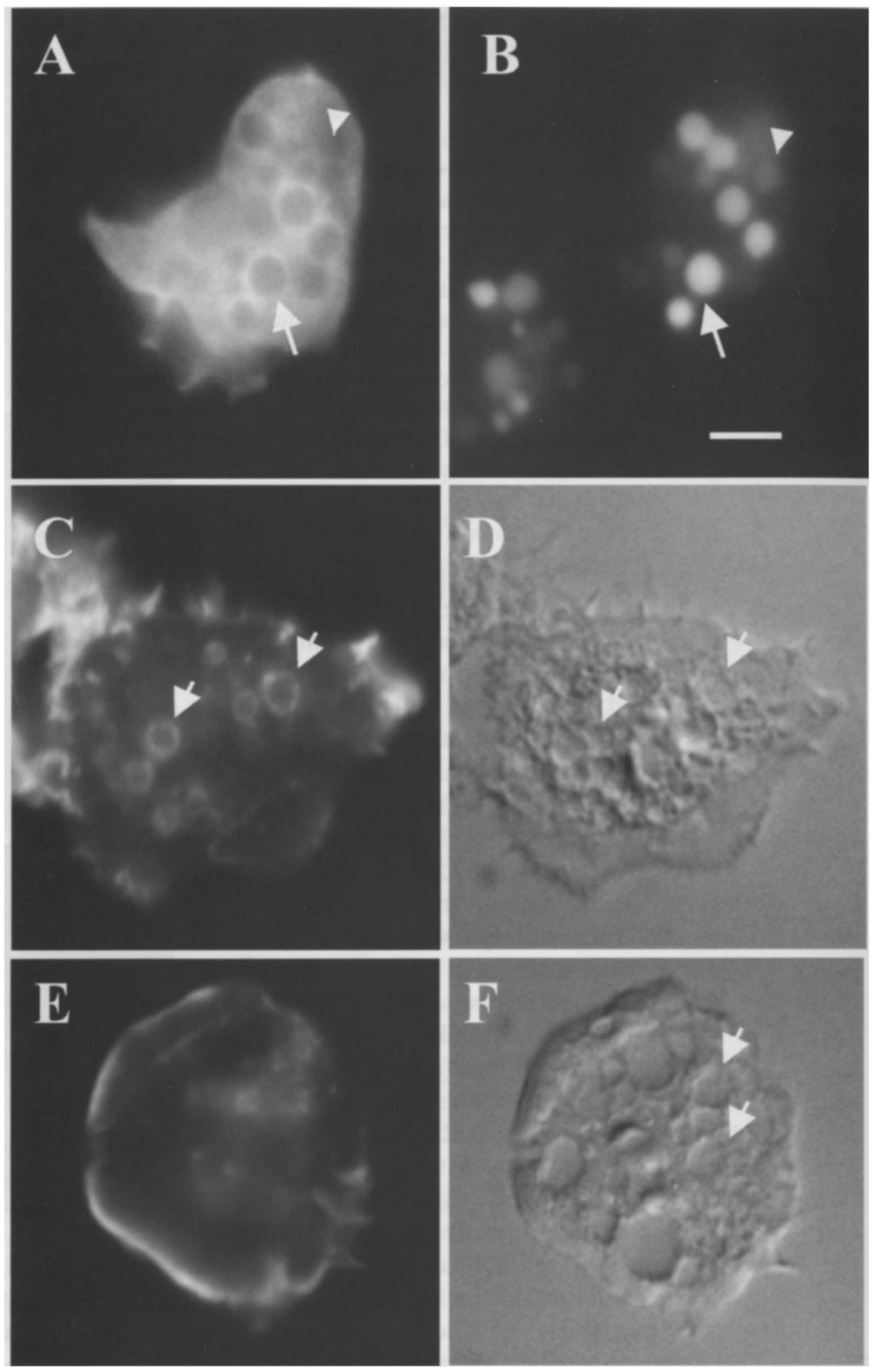

shown). Together, these results suggest that Scar does not associate stably with endo-lysosomes. However, our results do not exclude the possibility that Scar associates with vesicles in a transient manner, and this association is not very stable. If this is true, the methods used above to detect this interaction would not have yielded positive results.

The above data suggest that, by regulating F-actin polymerization, Scar plays major role in internalization of fluid and particles, and trafficking along the endosomal pathway. This hypothesis predicts that inhibition of actin polymerization by chemical means might result in phenotypic changes comparable to those observed in scar ${ }^{-}$cells. Accordingly, wildtype cells were treated with the drug cytochalasin A, which prevents polymerization of F-actin (Himes et al., 1976). Under these conditions, and as reported by others (Hacker et al., 1997), we observed a dose-dependent inhibition in the rate of fluid phase endocytosis and phagocytosis (results not shown). Interestingly, the $50 \%$ inhibitory concentration of cytochalasin

A for endocytosis was much lower than for phagocytosis $(0.2$ $\mu \mathrm{M}$ vs $2 \mu \mathrm{M}$ ), suggesting that, in Dictyostelium, a drug that prevents polymerization from the barbed ends of F-actin has a greater negative affect on fluid phase internalization than on the uptake of particles. Treating cells with cytochalasin A also caused a dose-dependent delay in exocytosis of fluid and inhibited the movement of fluid phase into and from acidic to more neutral $\mathrm{pH}$ compartments, as previously observed by others (Rauchenberger et al., 1997). Together, these results are consistent with the hypothesis that Scar functions to regulate both internalization of fluid and particles, and endosomal trafficking, perhaps by regulating the polymerization of $\mathrm{F}$ actin.

\section{Disruption of scar in a profilin null background imparts additional defects in fluid phase endocytosis}

Based on the available evidence indicating a potential 
Fig. 5. Cells with the $p I^{-} / I I^{-}$ $/$ scar ${ }^{-}$triple mutation are tight aggregate mutants and show abnormal F-actin staining. As described in Materials and Methods, strains were produced that were null for profilin I and profilin II and Scar

$(A, B)$ Development of profilin double mutants $\left(\mathrm{pI}^{-} / \mathrm{II}^{-}\right)$and triple mutants $\left(\mathrm{pI}^{-} / \mathrm{II}^{-} / \mathrm{scar} \mathrm{r}^{-}\right)$, respectively. The absence of Scar does not significantly alter the profilin-null developmental phenotype. However, cortical Factin staining as visualized with TRITC-phalloidin was significantly reduced in the triple mutant (D) relative to the double profilin mutant (C). TRITC-phalloidin staining of wild-type (E) and Scar null cells
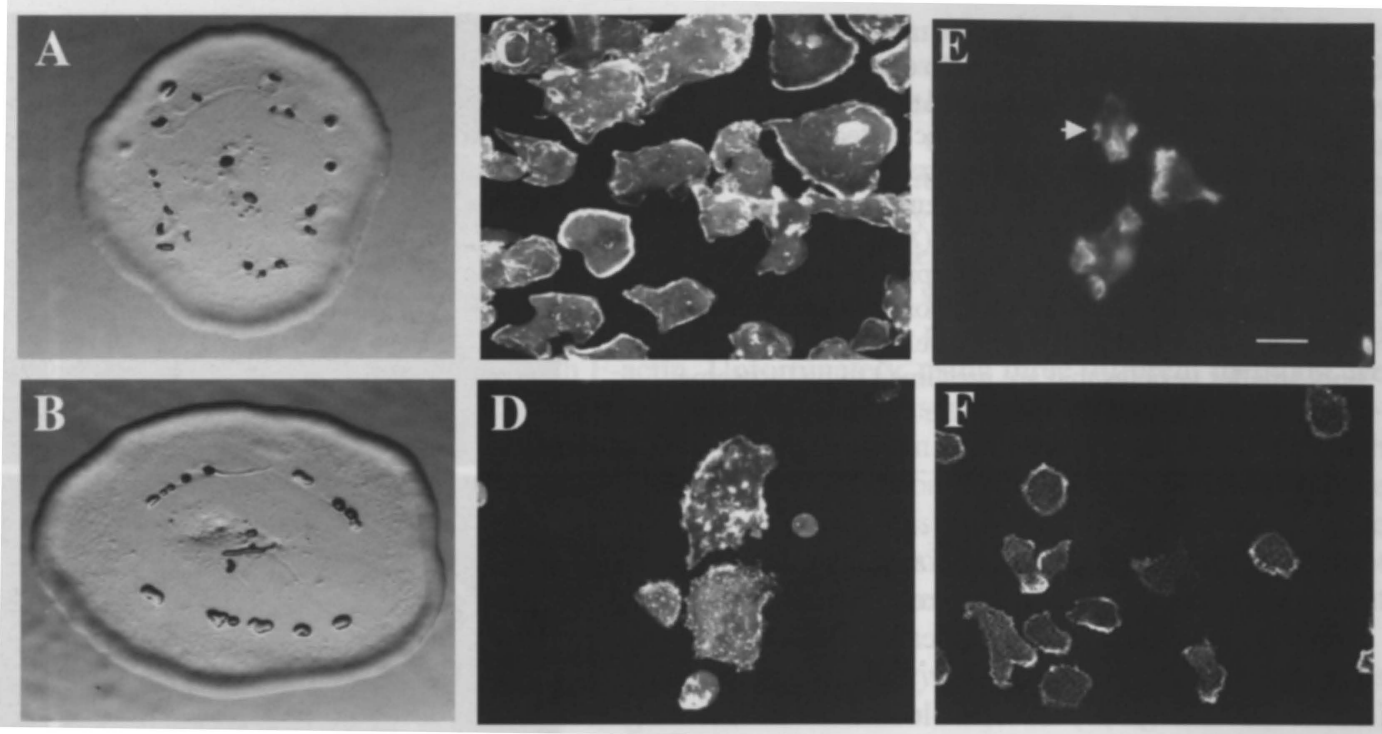

(F) are included for comparison. The arrow identifies a forming F-actin-rich macropinosome in control cells (E), structures that are absent from all the mutant cell lines. Bar, $10 \mu \mathrm{m}$.

functional connection between Scar and profilin in the regulation of the actin cytoskeleton (see Introduction), we constructed a triple mutant strain that lacked both scar and the two profilin-encoding genes. The triple mutant did not grow at all in suspension culture (data not shown), although growth on bacterial lawns seemed to be unimpaired. Profilin mutants are characterized by developing to the tight aggregate stage of development and growing as large, flat cells with increased amounts of cortical F-actin (Haugwitz et al., 1994). scar- cells have a largely opposite phenotype, producing multiple tipped structures during development, appearing smaller in suspension and having reduced levels of F-actin. The triple mutant cells do not develop beyond the tight aggregate stage (Fig. 5A,B), comparable to the developmental phenotype of the profilin mutants. However, although vegetative cells of the triple mutant were large (Fig. 5D) and flat, similar to the
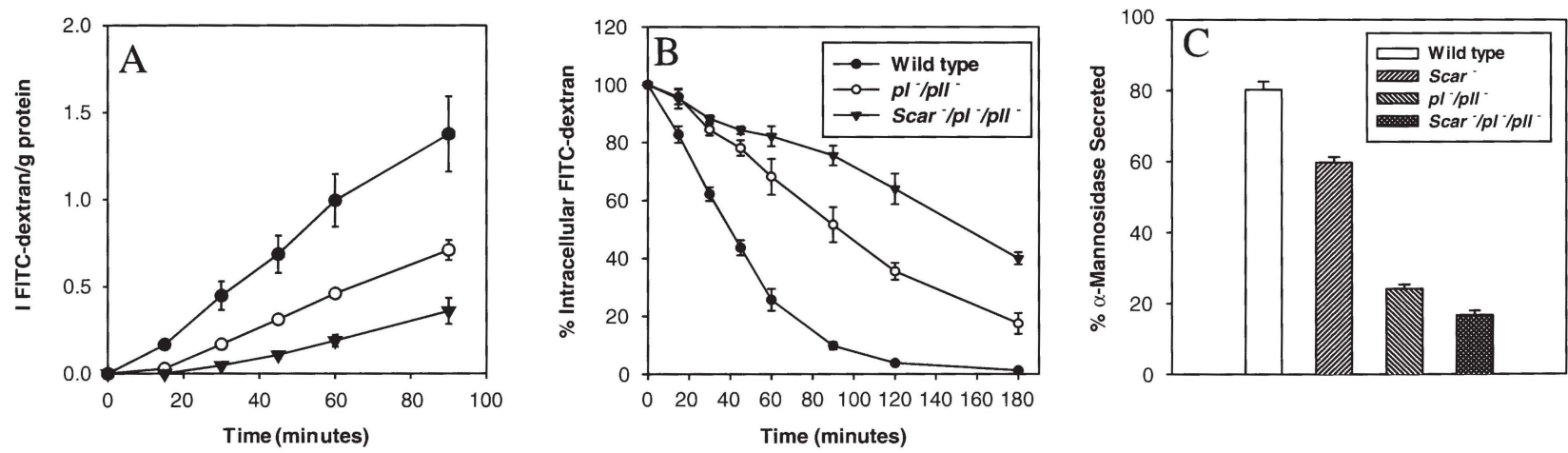

Fig. 6. Cells with the $\mathrm{pI}^{-} / \mathrm{II}^{-} / \mathrm{scar}^{-}$triple mutation are severely defective in fluid phase pinocytosis, exocytosis and lysosomal enzyme secretion. Cells were incubated with FITC-dextran and, at various times, the intracellular fluorescence was calculated as described in Materials and Methods; the averages of four independent experiments are shown (A). Alternatively, cells were loaded with FITC-dextran for 3 hours, washed and placed back in fresh growth medium. At various times, cells were collected, washed and the remaining intracellular FITC-dextran was measured (B). Finally, cells growing exponentially were collected by centrifugation and the intracellular and extracellular levels of $\alpha$ mannosidase were measured (C). (A) $\mathrm{pI}^{-} / \mathrm{II}^{-} / \mathrm{scar}^{-}$cells displayed a defect in pinocytosis compared with control cells, and $\mathrm{pI}^{-} / \mathrm{II}^{-} / \mathrm{scar}^{-}$cells showed an additive defect compared with Scar and profilin null mutants alone, supporting the hypothesis that these two proteins interact to regulate fluid internalization. (B) $\mathrm{pI}^{-} / \mathrm{II}^{-}$cells displayed an exocytic defect: $50 \%$ of the fluid phase remained inside the cell after 90 minutes post-chase (compared with 45 minutes for release of one half of the fluid phase from control cells). Cells with the $\mathrm{pI}^{-} / \mathrm{II}^{-} / \mathrm{scar}^{-}$triple mutation showed an additive exocytic defect: 50\% of the fluid phase remained inside the cell after 150 minutes into the chase period. After 3 hours into the chase period, none of the fluid phase remained in control cells, whereas $20 \%$ remained in the $\mathrm{pI}^{-} / \mathrm{II}^{-}$cells and $40 \%$ remained inside the $\mathrm{pI}^{-} /$ $I^{-} /$scar $^{-}$cells. (C) The steady state secretion rate of $\alpha$-mannosidase was calculated by comparing the extracellular enzymatic activity with the total enzymatic activity of the cells and supernatant from pelleted cells. At steady state, only $20 \%$ of the $\alpha$-mannosidase activity remained inside the cell, whereas $80 \%$ of the activity resided in the supernatant, owing to secretion of the lysosomal hydrolase. In scar ${ }^{-}$cells, $40 \%$ of the $\alpha$-mannosidase activity remained inside the cell, and for the $\mathrm{pI}^{-} / \mathrm{II}^{-}$cells, $30 \%$ of the enzymatic activity remained intracellular, indicating that there was a secretion defect in both of these strains. The $\mathrm{pI}^{-} / \mathrm{II}^{-} /$scar ${ }^{-}$cells displayed an additive secretion defect: only $15 \%$ of the $\alpha-$ mannosidase activity was found in the supernatant. 
Fig. 7. Cells with the $\mathrm{pI}^{-} / I \mathrm{I}^{-} /$scar $\mathrm{r}^{-}$triple mutation contain mainly small acidic endosomes. To examine the morphology of the endo-lysosomal system of $\mathrm{pI}^{-} / \mathrm{II}^{-}$and $\mathrm{pI}^{-} / \mathrm{II}^{-} / \mathrm{scar}^{-}$mutants, cells were incubated with FITCdextran for 1 hour, spotted on coverslips and prepared for phase contrast $(\mathrm{A}, \mathrm{C}, \mathrm{E})$ or fluorescence

(B,D,F) microscopy. Control cells (A,B) contained vesicles of many different sizes, representing pinosomes, macropinosomes, lysosomes and post-lysosomes. By contrast, $p I^{-} / I I^{-}$and $\mathrm{pI}^{-} / I I^{-} /$scar ${ }^{-}$cells (C-F) contained only smaller vesicles that are presumed to be lysosomes, because they stained with an acidic fluorophore (data not shown). Bar, $5 \mu \mathrm{m}$.

profilin mutants (Fig. 5C), the amount of cortical Factin appeared to be reduced relative to the profilin mutants, and the level appeared closer to that observed for the Scar null (Fig. 5F). In control cells, some of the cortical actin localizes to forming macropinocytic cups that are absent from all the mutant cell lines. These results suggested a complicated functional relationship between Scar and profilin, and prompted us to characterize the triple mutant further.

As shown in Fig. 6A, the rate of pinocytosis was reduced by $>60 \%$ in the $\mathrm{pI}^{-} / \mathrm{II}^{-}$null cells, as reported previously (Temesvari et al., 2000), and by $>80 \%$ in the $p I^{-} / I I^{-} /$scar $^{-}$mutant compared with wild-type cells (Fig. 6A). The triple mutant was also more severely defective in the release of fluid phase (Fig. 6B) and secretion of lysosomal enzymes (Fig. 6C) than either the scar null (Fig. 2) or the $p I^{-} / I I^{-}$null cells alone. These data suggest that both Scar and profilin play a positive role in fluid phase endocytosis, fluid phase exocytosis and lysosomal enzyme secretion, and their combined absence leads to an additive decrease in the rates of these processes. Unfortunately, attempts to measure the rate of fluid phase movement to and from acidic vesicular compartment were unsuccessful because the triple mutant internalized too little FITC-dextran. However, the triple mutant and the $\mathrm{pI}^{-} / \mathrm{II}^{-}$null mutant accumulated FITC-dextran in small vesicles similar in size to the acidic vesicles observed in the scar null strain (Fig. 7). Furthermore, in the triple mutant, these small vesicles were acidic (they accumulated Lysosensor Green), suggesting that, as observed for the scar null mutant, fluid accumulates in acidic lysosomes in the triple mutant (D.J.S. and J.C., unpublished).

\section{DISCUSSION}

In this report, we present evidence suggesting that Scar regulates multiple steps in the endo-lysosomal system of Dictyostelium. The uptake of latex beads and bacteria (phagocytosis), and of fluid phase (micro- and macropinocytosis), was decreased in scar cell-lines. In addition, the release of internalized fluid phase to and from lysosomes and post-lysosomes in the scar null cells was inhibited, and the movement of fluid phase from acidic to neutral $\mathrm{pH}$ compartments was also delayed. Actin plays an
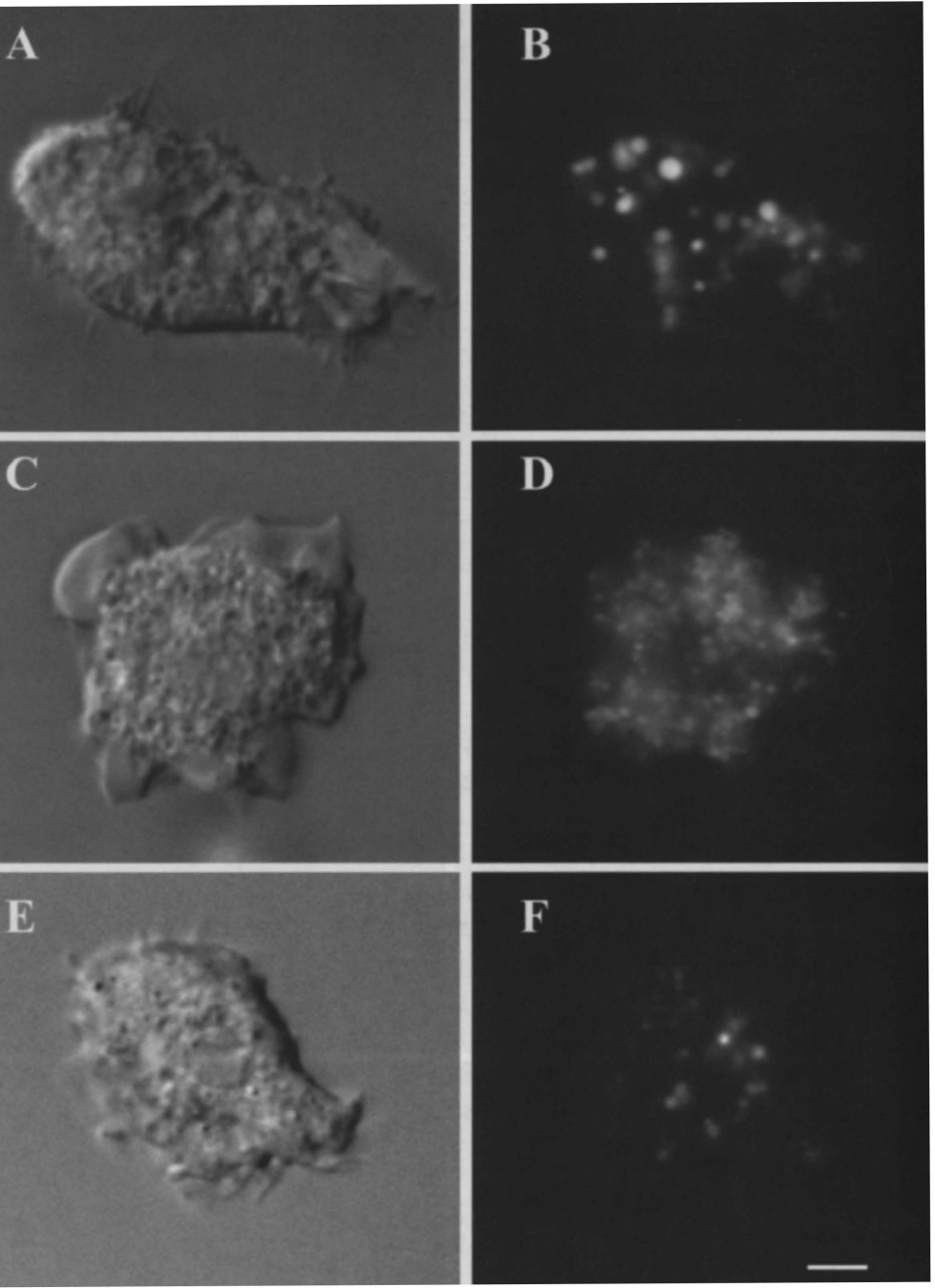

important role in all of these endo-lysosomal processes, as demonstrated by treatment with cytochalasin A, which prevents polymerization of actin. Inhibition of each endocytic process was similar to that observed in the scar null cells. Evidence was also presented suggesting that Scar and the actin monomer sequestering protein profilin (encoded by two genes) functionally interact with one another. Disruption of the two profilin genes together with the Scar gene resulted in additional defects in growth, fluid phase endocytosis and exocytosis, and the secretion of lysosomal enzymes (this report and Temesvari et al., 2000). Together, our results support the hypothesis that Scar and profilin interact to regulate F-actin polymerization, a process that plays an important role in multiple endocytic steps.

It has recently been reported that WASp regulates Fc $\gamma$ receptor mediated phagocytosis in peripheral blood monocytes and that WASp is recruited to the forming phagocytic cup (May et al., 2000; Lorenzi et al., 2000). Our results extend this observation to include the Scar proteins as being important in regulating phagocytosis. Although phagocytosis rates were greatly decreased in scar- cells, this process was still partially active. Additional WASp-like proteins have been identified in the Dictyostelium databases (C.L.S., unpublished; http://dictybase.org/dicty.html) and the activity of these proteins might partially compensate for the loss of Scar. 
We also observed a small but significant decrease in the rate of uptake of the fluid phase marker FITC-dextran, although the formation of macropinosomes was almost completely blocked. We therefore suggest that Scar might be equally important in the regulation of phagocytosis and macropinocytosis, and a Scar-independent non-macropinocytic endocytic process might partially compensate for the decrease in macropinocytosis. There is precedent for this in animal cells (Damke et al., 1995) and both clathrin-dependent and clathrin-independent processes appear to operate in Dictyostelium (Ruscetti et al., 1994; Hacker et al., 1997).

The absence of Scar in Dictyostelium results in a roughly $50 \%$ reduction in the levels of F-actin (Bear et al., 1998), suggesting that Scar plays a positive role in actin polymerization and that F-actin dynamics are critical in regulating macropinocytosis and phagocytosis. In support of this, several studies have demonstrated that F-actin binding proteins and F-actin accumulate around the forming phagocytic and macropinocytic cups (Maniak et al., 1995; Hacker et al., 1997; Rupper et al., 2001). Furthermore, the addition to cultures of cytochalasin A (an agent that prevents F-actin polymerization from barbed ends of growing filaments) inhibited both phagocytosis and fluid phase endocytosis (Maniak et al., 1995; Hacker et al., 1997). Together with previous published studies (Machesky et al., 1999), these data are consistent with the proposed role for Scar as an inducer of actin polymerization and that it is in this role that Scar affects phagocytosis, macropinocytosis and cell motility (C.L.S., unpublished).

We also observed severe defects in the endocytic trafficking pathways of $s c a r^{-}$cells: control cells released internalized fluid phase markers and lysosomal enzymes at a significantly faster rate than scar $^{-}$cells. These data were not unexpected, given that Scar has been proposed to regulate F-actin polymerization, and that we (this study) and others (Rauchenberger et al., 1997) have shown that actin polymerization might be important for a late stage of endo-lysosomal trafficking. We propose that actin polymerization regulates a late step in endosomal trafficking step that might involve fusion of lysosomes. Consistent with this latter observation, we observed a greater accumulation of small acidic vesicles in scar cells than in control cells. The accumulation of acidic lysosomes and a decrease in the number of post-lysosomes has been observed previously in cell lines that were null for DdPIK1 and DdPIK2, two of the three known phosphatidylinositol (PtdIns) 3-kinase genes in Dictyostelium (Buczynski et al., 1997), and in cell lines overexpressing the Rho-like GTPase RacC (Seastone et al., 1998). Both of these classes of proteins were also demonstrated in these reports to regulate the dynamics of $\mathrm{F}$-actin and there appears to be a functional interaction between Scar and RacC (D.J.S. et al., unpublished). Maniak and co-workers have demonstrated that F-actin-binding proteins ring macropinosomes and postlysosomes but not acidic lysosomes (Hacker et al., 1997; Rauchenberger et al., 1997), a result that we have confirmed here by examining F-actin directly. Together, these results strongly suggest that F-actin polymerization might directly regulate the fusion of lysosomes to form post-lysosomes, a process that is dependent on Scar.

One possible way that $\mathrm{F}$-actin polymerization could regulate the fusion of lysosomes would be to facilitate the interaction between these acidic vesicles. Taunton and co-workers
(Taunton et al., 2000) have recently found that N-WASp is recruited to acidic vesicles (most likely endosomes and lysosomes), and this facilitated the assembly of actin to form actin comet tails that propel these vesicles. Scar might play a comparable role in Dictyostelium and the motile lysosomes might collide more frequently to trigger fusion. Consistent with this hypothesis, Scar null cells were devoid of vesicles that were ringed with F-actin, whereas control cells contained endo-lysosomes the size of post-lysosomes that were ringed with F-actin. Unfortunately, using three different methods, we were not able to detect an association between Scar and endolysosomes. This might mean that Scar never associates with endo-lysosomes, a conclusion we do not favor based on the studies alluded to above. Instead, we favor the idea that the association of Scar with vesicles might be transient and not stable, and the approaches we used to detect association might thus not have been optimal.

Disruption of the two Dictyostelium profilin-encoding genes resulted in a twofold increase in F-actin (Haugwitz et al., 1994) and a decrease in macropinocytosis and fluid phase efflux (this report and Temesvari et al., 2000). Deletion of the scar gene in the profilin null background resulted in a further decrease in endocytosis and fluid phase release. We have proposed that macropinocytosis requires, in addition to Scar (this report), profilin (Temesvari et al., 2000) and the PtdIns 3-kinases, DdPIK1 and DdPIK2 (Rupper et al., 2001). Although the exact role of profilin has not been defined, we propose that this protein binds PtdIns $(4,5) P_{2}$ and perhaps recruits DdPIK1 and DdPIK2 to generate $\operatorname{PtdIns}(3,4,5) P_{3}$, and this product stimulates the process of macropinocytosis (Rupper et al., 2001). Scar might bind to the plasma membrane and recruit profilin and PtdIns 3-kinases to stimulate F-actin polymerization to drive the formation of the macropinosome, and the combined absence of both types of proteins would have a profound negative affect on fluid phase internalization. Alternatively, profilin might interact with nascent macropinosomal cups and recruit Scar, which could aid in actin polymerization.

Both profilin and Scar are required for efficient efflux of internalized fluid phase. Not surprisingly, the combined absence of Scar and profilin resulted in greater defects in fluid phase exocytosis. This further supports the argument that Factin dynamics play a critical role in a late step in the endosomal pathway leading to release of internalized fluid, and that profilin and Scar both play a role in this process. Our hypothesis is that profilin and Scar interact functionally, and the absence of both proteins predictably has a more drastic affect on efflux than the absence of either protein alone. However, our results do not preclude the possibility that both proteins act in parallel to regulate endocytic processes.

In summary, we have provided evidence that Scar plays an important role in the regulation of multiple steps in the endocytic membrane trafficking, including phagocytosis, fluid phase endocytosis (particularly macropinocytosis) and a late step in the endosomal pathway in $D$. discoideum. Scar most probably has its effects through its ability to regulate F-actin polymerization. We also found that the actin-monomersequestering protein profilin played an important role in these endo-lysosomal processes, and our evidence suggests that profilin and Scar both functionally contribute to regulate fluid phase endocytosis and endosomal membrane trafficking. 
Future studies will be directed at identifying additional effector proteins and defining the biochemical mechanisms that regulate these membrane trafficking events.

The work presented here was supported by a grant to JC from the NIH (DK39232) and a grant to KS from the NIH (GM45705).

\section{REFERENCES}

Anton, I. M., Lu, W., Mayer, B. J., Ramesh, N. and Geha, R. S. (1998) The Wiskott-Aldrich syndrome protein-interacting protein (WIP) binds to the adaptor protein Nck. J. Biol Chem. 273, 20992-20995.

Aspenstrom, P., Lindberg, U. and Hall, A. (1996). Two GTPases, Cdc42 and Rac, bind directly to a protein implicated in the immunodeficiency disorder Wiskott-Aldrich syndrome. Curr. Biol. 6, 70-75.

Aubry, L., Klein, G. and Satre, M. (1993). Endo-lysosomal acidification in Dictyostelium discoideum amoebae. Effects of two endocytosis inhibitors: caffeine and cycloheximide. Eur. J. Cell Biol. 61, 225-228.

Bear, J. E., Rawls, J. F. and Saxe, C. L. (1998). SCAR, a WASP-related protein, isolated as a suppressor of receptor defects in late Dictyostelium development. J. Cell Biol. 142, 1325-1335.

Buczynski, G., Grove, B., Nomura, A., Kleve, M., Bush, J., Firtel, R. A. and Cardelli, J. (1997). Inactivation of two Dictyostelium discoideum genes, $D d P I K 1$ and $D d P I K 2$, encoding proteins related to mammalian phosphatidylinositide 3-kinases, results in defects in endocytosis, lysosome to postlysosome transport and actin cytoskeleton organization. J. Cell Biol. 136, 1271-1286.

Carlsson, L., Nystrom, L. E., Sundkvist, I., Markey, F. and Lindberg, U. (1977). Actin polymerizability is influenced by profilin, a low molecular weight protein in non-muscle cells. J. Mol. Biol. 115, 465-483.

Damke, H., Baba, T., van der Bliek, A. M. and Schmid, S. L. (1995). Clathrin-independent pinocytosis is induced in cells overexpressing a temperature-sensitive mutant of dynamin. J. Cell. Biol. 131, 69-80

Derry, J. M., Ochs, H. D. and Francke, U. (1994). Isolation of a novel gene mutated in Wiskott-Aldrich syndrome. Cell 78, 635-644; [erratum Cell 79, 922]

Hacker, U., Albrecht, R. and Maniak, M. (1997). Fluid-phase uptake by macropinocytosis in Dictyostelium. J. Cell Sci. 110, 105-112.

Haugwitz, M., Noegel, A. A., Karakesisoglou, J. and Schleicher, M. (1994). Dictyostelium amoebae that lack G-actin-sequestering profilins show defects in F-actin content, cytokinesis and development. Cell 79, 303-314

Himes, R. H., Kersey, R. N., Ruscha, M. and Houston, L. L. (1976). Cytochalasin A inhibits the in vitro polymerization of brain tubulin and muscle actin. Biochem. Biophys. Res. Commun. 68, 1362-1370.

Jenne, N., Rauchenberger, R., Hacker, U., Kast, T. and Maniak, M. (1998). Targeted gene disruption reveals a role for vacuolin B in the late endocytic pathway and exocytosis. J. Cell Sci. 111, 61-70.

Kirchhausen, T. and Rosen, F. S. (1996). Disease mechanism: unravelling Wiskott-Aldrich syndrome. Curr. Biol. 6, 676-678.

Kolluri, R., Tolias, K. F., Carpenter, C. L., Rosen, F. S. and Kirchhausen, T. (1996). Direct interaction of the Wiskott-Aldrich syndrome protein with the GTPase Cdc42. Proc. Natl. Acad. Sci. USA 93, 5615-5618.

Kubler, E. and Riezman, H. (1993). Actin and fimbrin are required for the internalization step of endocytosis in yeast. EMBO J. 12, 2855-2862.

Lamaze, C., Fujimoto, L. M., Yin, H. L. and Schmid, S. L. (1997). The actin cytoskeleton is required for receptor-mediated endocytosis in mammalian cells. J. Biol. Chem. 272, 20332-20335.

Lorenzi, R., Brickell, P. M., Katz, D. R., Kinnon, C. and Thrasher, A. J. (2000). Wiskott-Aldrich syndrome protein is necessary for efficient IgGmediated phagocytosis. Blood 95, 2943-2946.

Machesky, L. M., Atkinson, S. J., Ampe, C., Vandekerckhove, J. and Pollard, T. D. (1994). Purification of a cortical complex containing two unconventional actins from Acanthamoeba by affinity chromatography on profilin-agarose. J. Cell Biol. 127, 107-115.

Machesky, L. M., Mullins, R. D., Higgs, H. N., Kaiser, D. A., Blanchoin, L., May, R. C., Hall, M. E. and Pollard, T. D. (1999). Scar, a WASprelated protein, activates nucleation of actin filaments by the Arp2/3 complex. Proc. Natl. Acad. Sci. USA 96, 3739-3744.

Maniak, M., Rauchenberger, R., Albrecht, R., Murphy, J. and Gerisch, G. (1995). Coronin involved in phagocytosis: dynamics of particle-induced relocalization visualized by a green fluorescent protein Tag. Cell $\mathbf{8 3}, 915-$ 924.
May, R. C., Caron, E., Hall, A. and Machesky, L. M. (2000). Involvement of the Arp2/3 complex in phagocytosis mediated by FcgammaR or CR3. Nat. Cell Biol. 2, 246-248.

Miki, H., Miura, K. and Takenawa, T. (1996). N-WASP, a novel actindepolymerizing protein, regulates the cortical cytoskeletal rearrangement in a PtdIns $(4,5) \mathrm{P}_{2}$-dependent manner downstream of tyrosine kinases. EMBO J. 15, 5326-5335.

Miki, H., Sasaki, T., Takai, Y. and Takenawa, T. (1998). Induction of filopodium formation by a WASP-related actin-depolymerizing protein $\mathrm{N}$ WASP. Nature 391, 93-96.

Moreau, V., Galan, J. M., Devilliers, G., Haguenauer-Tsapis, R. and Winsor, B. (1997). The yeast actin-related protein Arp2p is required for the internalization step of endocytosis. Mol. Biol. Cell 8, 1361-1375.

Mullins, R. D. (2000). How WASP-family proteins and the $\operatorname{arp} 2 / 3$ complex convert intracellular signals into cytoskeletal structures. Curr. Opin. Cell Biol. 12, 91-96.

Mullins, R. D., Stafford, W. F. and Pollard, T. D. (1997). Structure, subunit topology and actin-binding activity of the Arp2/3 complex from Acanthamoeba. J. Cell Biol. 136, 331-343.

Mullins, R. D., Heuser, J. A. and Pollard, T. D. (1998). The interaction of Arp2/3 complex with actin: nucleation, high affinity pointed end capping and formation of branching networks of filaments. Proc. Natl. Acad. Sci. USA 95, 6181-6186

Ochs, H. D., Slichter, S. J., Harker, L. A., Von Behrens, W. E., Clark, R. A. and Wedgwood, R. J. (1980). The Wiskott-Aldrich syndrome: studies of lymphocytes, granulocytes and platelets. Blood 55, 243-252.

Padh, H., Ha, J., Lavasa, M. and Steck, T. L. (1993). A post-lysosomal compartment in Dictyostelium discoideum. J. Biol. Chem. 268, 6742-6747.

Pang, K., Lee, E. and Knecht, D. (1998). Use of a fusion protein between GFP and an actin-binding domain to visualize transient filamentous-actin structures. Curr. Biol. 8, 405-408

Ramesh, N., Anton, I. M., Hartwig, J. H. and Geha, R. S. (1997). WIP, a protein associated with Wiskott-Aldrich syndrome protein, induces actin polymerization and redistribution in lymphoid cells. Proc. Natl. Acad. Sci. USA 94, 14671-14676.

Rauchenberger, R., Hacker, U., Murphy, J., Niewohner, J. and Maniak, M. (1997) Coronin and vacuolin identify consecutive stages of a late, actincoate endocytic compartment in Dictyostelium. Curr. Biol. 7, 215-218

Rivero-Lezcano, O. M., Marcilla, A., Sameshima, J. H. and Robbins, K. C. (1995). Wiskott-Aldrich syndrome protein physically associates with Nck through Src homology 3 domains. Mol. Cell Biol. 15, 5725-5731.

Rohatgi, R., Ma, L., Miki, H., Lopez, M., Kirchhausen, T., Takenawa, T. and Kirschner, M. W. (1999). The interaction between N-WASP and the Arp2/3 complex links Cdc42-dependent signals to actin assembly. Cell. 97, 221-231.

Rupper, A., Lee, K., Knecht, D. and Cardelli, J. (2001). Sequential activities of PI 3-kinase, PKB/Akt and Rab7 during macropinosome formation in Dictyostelium. Mol. Biol. Cell (in press).

Ruscetti, T., Cardelli, J. A., Niswonger, M. L. and O'Halloran, T. J. (1994). Clathrin heavy chain functions in sorting and secretion of lysosomal enzymes in Dictyostelium discoideum. J. Cell Biol. 126, 343-352.

Saxe, C. L., Ginsburg, G. T., Louis, J. M., Johnson, R., Devreotes, P. N. and Kimmel, A. R. (1993) CAR2, a prestalk cAMP receptor required for normal tip formation and late development of Dictyostelium discoideum. Genes Dev. 7, 262-272.

Seastone, D. J., Lee, E., Bush, J., Knecht, D. and Cardelli, J. (1998). Overexpression of a novel Rho family GTPase, RacC, induces unusual actinbased structures and positively affects phagocytosis in Dictyostelium discoideum. Mol. Biol. Cell 9, 2891-2904.

Seastone, D. J., Zhang, L., Buczynski, G., Rebstein, P., Weeks, G., Spiegelman, G. and Cardelli, J. (1999). The small $M_{\mathrm{r}}$ Ras-like GTPase Rapl and the phospholipase C pathway act to regulate phagocytosis in Dictyostelium discoideum. Mol. Biol. Cell 10, 393-406.

She, H. Y., Rockow, S., Tang, J., Nishimura, R., Skolnik, E. Y., Chen, M., Margolis, B. and Li, W. (1997). Wiskott-Aldrich syndrome protein is associated with the adapter protein Grb2 and the epidermal growth factor receptor in living cells. Mol. Biol. Cell 8, 1709-1721.

Stewart, D. M., Tian, L. and Nelson, D. L. (1999). Mutations that cause the Wiskott-Aldrich syndrome impair the interaction of Wiskott-Aldrich syndrome protein (WASP) with WASP interacting protein. J. Immunol. 162, 5019-5024.

Suetsugu, S., Miki, H. and Takenawa, T. (1998). The essential role of profilin in the assembly of actin for microspike formation. EMBO J. 17, 6516-6526. Sun, T. J., Van Haastert, P. J. and Devreotes, P. N. (1990). Surface cAMP 
receptors mediate multiple responses during development in Dictyostelium: evidenced by antisense mutagenesis. J. Cell Biol. 110, 1549-1554.

Svitkina, T. M. and, Borisy, G. G. (1999). Arp $2 / 3$ complex and actin depolymerizing factor/cofilin in dendritic organization and treadmilling of actin filament array in lamellipodia. J. Cell Biol. 145, 1009-1026.

Symons, M., Derry, J. M., Karlak, B., Jiang, S., Lemahieu, V., McCormick, F., Francke, U. and Abo, A. (1996). Wiskott-Aldrich syndrome protein, a novel effector for the GTPase CDC42Hs, is implicated in actin polymerization. Cell $\mathbf{8 4}, \mathbf{7 2 3 - 7 3 4 .}$

Taunton, J., Rowning, B. A., Coughlin, M. L., Wu, M., Moon, R. T. Mitchison, T. J. and Larabell, C. A. (2000). Actin-dependent propulsion of endosomes and lysosomes by recruitment of N-WASP. J. Cell Biol. 148:519-30.

Temesvari, L., Rodriguez-Paris, J., Bush, J., Steck, T. and Cardelli, J. (1994). Characterization of lysosomal membrane proteins of Dictyostelium discoideum. A complex population of acidic integral membrane glycoproteins, Rab GTP-binding proteins and vacuolar ATPase subunits. $J$. Biol. Chem. 269, 25719-25727.
Temesvari, L., Zhang, L., Fodera, B., Klaus-Peter, J., Schleicher, M. and Cardelli, J. (2000). Inactivation of $\operatorname{lmpA}$, encoding a LIMPIIrelated endosomal protein, suppresses the internalization and endosomal trafficking defects in profilin-null mutants. Mol. Biol. Cell 11, 20192031.

Vaduva, G., Martinez-Quiles, N., Anton, I. M., Martin, N. C., Geha, R. S., Hopper, A. K. and Ramesh, N. (1999). The human WASP-interacting protein, WIP, activates the cell polarity pathway in yeast. J. Biol. Chem. 274, 17103-17108.

Vinson, V. K., De La Cruz, E. M., Higgs, H. N. and Pollard, T. D. (1998). Interactions of Acanthamoeba profilin with actin and nucleotides bound to actin. Biochemistry 37, 10871-10880.

Weiner, O. D., Servant, G., Welch, M. D., Mitchison, T. J., Sedat, J. W. and Bourne, H. R. (1999). Spatial control of actin polymerization during neutrophil chemotaxis. Nat. Cell Biol. 1, 75-81.

Welch, M. D., Iwamatsu, A. and Mitchison, T. J. (1997). Actin polymerization is induced by Arp $2 / 3$ protein complex at the surface of Listeria monocytogenes. Nature 385, 265-269. 